\title{
ANÁLISE DO IMPACTO DO FLUXO DE CAIXA LIVRE SOBRE $O$ RETORNO ACIONÁRIO DAS COMPANHIAS DE CAPITAL ABERTO NO MERCADO ACIONÁRIO BRASILEIRO
}

\section{ANALYSIS OF FREE CASH FLOW IMPACT ON EQUITY RETURN OF LISTED COMPANIES IN THE BRAZILIAN STOCK MARKET}

0 artigo foi aprovado e apresentado no XVIII USP International Conference in Accounting com o título: "Significância dos indicadores da análise fundamentalista para 0 retorno acionário das companhias de capital aberto negociadas no mercado brasileiro", realizado de 25/07 a 27/07 de 2018, em São Paulo (SP).

\section{RESUMO}

O objetivo desta pesquisa é verificar se o indicador fluxo de caixa livre/preço (FCF/P) é capaz de prever o retorno acionário das companhias de capital aberto do mercado brasileiro. Como esse indicador é amplamente utilizado em modelos de fluxo de caixa descontado (FCD), buscou-se testar seu poder preditivo tanto no período corrente, como também com períodos defasados, juntamente com outras variáveis fundamentalistas. Foram analisados dados trimestrais de 2008 a 2016 de 245 ações ordinárias e 157 ações de outras classes em regressão linear múltipla através de quatro estimações: POLS, efeito fixo robusto, efeito aleatório robusto e painel dinâmico. Os principais resultados obtidos foram: a significância estatística do fluxo de caixa livre/preço (FCF/P) para prever o retorno acionário com um e três trimestres de defasagem pelo método em painel dinâmico. Encontrou-se, pelas outras estimações, bom poder preditivo do retorno acionário para as variáveis: fluxo de caixa livre/preço (FCF/P), liquidez corrente (LIQ), endividamento (END), margem bruta (MB), lucro-preço (L/P), dividend yield (DY), vendas preço (V/P) e book-to-market (BM). As limitações da pesquisa foram: a pequena quantidade de amostra, pois há poucas companhias de capital aberto no Brasil, e as mudanças das políticas contábeis no período. A partir dos resultados encontrados, investidores e analistas podem fazer projeções dos retornos das empresas, além de utilizar o modelo para construção de portfólios. O presente trabalho contribui com a literatura empírica da contabilidade no mercado de capitais por introduzir o índice fluxo de caixa livre/ preço (FCF/P) e revelar seu poder preditivo sobre o retorno acionário (RET).

Palavras chave: Análise Fundamentalista, Fluxo de Caixa Livre/Preço, Retorno Acionário, Mercado de Capitais.

\begin{abstract}
The objective of this research is to verify if the free cash flow / price $(F C F / P)$ indicator is able to predict the stock return of publicly traded companies in the Brazilian market. As this indicator is widely used in discounted cash flow (CDF) models, it was sought to test its predictive power both in the current period and also with lagged periods, along with other fundamentalist variables. We analyzed quarterly data from 2008 to 2016 of 245 common shares and 157 shares of other classes in multiple linear regression through four estimates: POLS, robust fixed effect, robust random effect and dynamic panel. The main results were the statistical significance of the free / price cash flow $(F C F / P)$ to predict the stock return with one and three quarters of lag by the dynamic panel method. We found good predictive power of the stock return for the variables: free cash flow / price (FCF/P), current liquidity (LIQ), indebtedness (END), gross margin $(M B)$, profit-price $(L / P)$, dividend yield $(D Y)$, sales price (V/P) and book-to-market (BM). The limitations of the survey were the small amount of sample, as there are few publicly traded companies in Brazil, and changes in accounting policies in the period. From the results found, investors and analysts can make projections of companies' returns, in addition to using the model to build portfolios. The present work contributes with the empirical literature of capital market accounting for introducing the free cash flow/price index $(F C F / P)$ and revealing its predictive power over the stock return (RET).
\end{abstract}

Rafael Antonio Moutinho

Graduado em Ciências Contábeis pela Universidade de São Paulo na Faculdade de Economia, Administração e Contabilidade de Ribeirão Preto (FEARP-USP). Contato: Avenida Bandeirantes, 3900, Monte Alegre, Ribeirão Preto, SP, CEP: 14.040-905. E-mail: rafaelmoutinho@outlook.com

\section{Vinícius Medeiros Magnani} Mestre em Controladoria e Contabilidade pela Universidade de São Paulo (USP) na Faculdade de Economia, Administração e Contabilidade de Ribeirão Preto (FEA RP). Graduado em Economia Empresarial e Controladoria também pela FEARP/ USP, com Habilitação em Economia Ênfase em Negócios Internacionais e em Contabilidade - Ênfase em Finanças. Docente do curso de Ciências Contábeis do Centro Universitário Moura Lacerda (CUML). Contato: Avenida Bandeirantes, 3900, Monte Alegre, Ribeirão Preto, SP, CEP: 14.040-905. E-mail: vinicius magnani@hotmail.com

\section{Marcelo Augusto Ambrozini} Professor Livre-Docente da Universidade de São Paulo (USP), Faculdade de Economia, Administração e Contabilidade de Ribeirão Preto (FEARP) - Departamento de Contabilidade. Professor do Programa de Pós-Graduação em Controladoria e Contabilidade (PPGCC) da FEA-RP/USP. Doutor em Administração de Organizações, Mestre em Controladoria e Contabilidade e bacharel em Ciências Contábeis pela FEARP/USP. Contato: Avenida Bandeirantes, 3900 - Sala 75-C2, Monte Alegre, Ribeirão Preto, SP, CEP: 14.040-905. E-mail: marceloambrozini@usp.br

Keywords: Fundamental Analysis, Free Cash Flow / Price, Return on Equity, Capital Markets. 


\section{INTRODUÇÃO}

O mercado de ações tem se desenvolvido de maneira vigorosa no Brasil (TAVARES; SILVA, 2012), beneficiando empresas, por tratar-se de uma fonte relevante de financiamento; e investidores, que podem diversificar sua carteira, reduzindo o seu risco. Entretanto, no caso dos investidores, seu sucesso no mercado de capitais depende de sua capacidade de alocação dos ativos de modo que o seu retorno seja maximizado.

Uma das estratégias mais utilizadas na avaliação de ações é a análise fundamentalista, que é um conjunto de técnicas baseadas em informações contábil-financeiras das empresas para identificar as melhores alternativas de investimento no mercado de ações. Ainda que o desempenho de uma empresa não possa ser mensurado e projetado utilizando somente suas demonstrações financeiras publicamente disponíveis (TAVARES; SILVA, 2012; KOTHARI, 2001), há um foco nas informações contábeis para a avaliação de ações, pois, trata-se de informações que estão publicamente disponíveis aos investidores (PENMAN, 1992).

O principal foco da análise fundamentalista é a avaliação do valor da empresa para identificar ações subavaliadas, por meio de direcionadores de valor, como lucros, riscos, crescimento e posições competitivas (LEV; THIAGARAJAN, 1993; KOTHARI, 2001). Para Kothari (2001), as pesquisas científicas no mercado de capitais envolvendo a análise fundamentalista têm se tornado extremamente populares, já que a literatura de economia e finanças têm mostrado evidências contra a Hipótese de Mercado Eficiente (HME). Assim, Yan e Zheng (2017) ponderam que pesquisadores de finanças têm dedicado tempo e esforço na busca por padrões dos retornos acionários, que não podem ser explicados pelos modelos tradicionais de precificação de ativos.

Em relação aos trabalhos que testaram o poder explicativo das variáveis da análise fundamentalista, têm-se, no Brasil: Nagano, Merlo e Silva (2003), Tavares e Silva (2012) e Evrard e Cruz (2016); e, no mundo, Ou e Penman (1989a; 1989b), Holthausen e Larcker (1992), Lev e Thiagarajan (1993), Abarbanell e Bushee (1997; 1998), Piotroski (2000), Mohanram (2005). Em geral, estes estudos encontraram que as variáveis da análise fundamentalistas e indicadores contábeis são capazes de explicar os retornos acionários ou os retornos anormais das companhias e, esses autores, defendem seu uso em estratégias de investimento.

Na busca por um conjunto de variáveis que sejam capazes de prever o retorno acionário das empresas de capital aberto no Brasil, a presente pesquisa inova por utilizar como variável de interesse o fluxo de caixa livre/preço (FCF/P) para testar seu impacto dentro de um modelo que inclui, como variáveis de controle, as variáveis fundamentalistas comumente utilizadas para a análise contábil-financeira das empresas.

Com o propósito de evidenciar a relevância estatística para a previsão do retorno acionário (RET), o presente trabalho utiliza, entre outros métodos, a estimação do modelo pela metodologia GMM (generalized method of moments), pois, a intuição é que o fluxo de caixa livre/preço (FCF/P) não explique somente o retorno acionário (RET) no mesmo período, já que essa variável não é de conhecimento dos usuários das demonstrações financeiras no mesmo período, assim, procura-se, com essa estimação, defasar o FCF/P seguindo o modelo proposto por Arellano e Bond (1991).

Partindo dessa problemática, a pergunta da pesquisa é formulada do seguinte modo: a variável fundamentalista fluxo de caixa livre/preço (FCF/P) impacta o retorno acionário das empresas de capital aberto negociadas no mercado de capitais brasileiro? Assim, objetivo do trabalho é verificar a significância estatística do fluxo de caixa livre/preço (FCF/P) em comparação com as outras variáveis comumente utilizadas pela literatura na previsão do retorno acionário das companhias de capital aberto negociadas no mercado brasileiro.

O presente trabalho contribui para que os usuários das informações contábeis tenham melhores direcionadores ao analisar as demonstrações financeiras com base na utilização da análise fundamentalista como estratégias de investimentos. O papel da contabilidade como provedora de informações para o mercado de capitais tem sido objeto de trabalhos recorrentes, sendo sua relevância justificada pela importância da informação contábil-financeira na tomada de decisão dos investidores e da recomendação dos analistas de investimento, principalmente aqueles que utilizam a estratégia de investimento baseada na análise fundamentalista para encontrar empresas com maior potencial econômico-financeiro (KOTHARI, 2001; RANGEL, 2004; FERREIRA, 2010; CPC 00-R1, 2011).

\section{REVISÃO DA LITERATURA}

A partir da premissa de diversificação de Harry Markowitz (1952), com contribuições posteriores de Treynor (1961) e Tobin (1958), William Sharpe propôs, no ano de 1964, um modelo para determinação dos preços dos ativos financeiros sob condições de risco, fornecendo as bases para o modelo que, após as contribuições de Lintner (1965), Mossin (1966) e Black (1972), viria a ser conhecido por CAPM (Capital Asset Pricing Model).

Duas premissas fundamentais foram propostas no trabalho de Sharpe (1964): (i) a existência de uma taxa de juros comum a todos os investidores, tanto para tomar recursos como para aplicar fundos e (ii) expectativas homogêneas quanto aos retornos futuros e volatilidade dos retornos por parte de todos os investidores. Baseado nessas premissas, o principal argumento que sustenta o modelo CAPM é de que, em condições de equilíbrio de mercado, haverá uma relação linear simples entre a expectativa de retorno e o desvio padrão dos retornos dos ativos.

Após a proposição do Modelo CAPM, diversos pesquisadores passaram a acrescentar ao modelo variáveis fundamentalistas capaz de aumentar o poder de previsão dos retornos das ações. Nesse sentido, há na literatura da área uma infinidade de 
estudos que analisaram a influência de outras variáveis fundamentalistas da firma e/ou macroeconômicas na explicação dos retornos dos ativos no mercado acionário, além do risco-beta, que ficaram conhecidos como modelos multifatoriais. Fama e French (1993) acrescentaram o tamanho da firma e o índice book-to-market ao prêmio pelo risco de mercado do CAPM, cujo modelo ficou conhecido como modelo de 3-fatores de Fama e French. Posteriormente, Jegadeesh e Titman (1993) e Fama e French (1996) acrescentaram o fator momento aos 3-fatores de Fama e French no que viria a ser chamado de modelo de 4 fatores.

Ou e Penman (1989a) verificaram um grande número de indicadores contábeis e da análise fundamentalista no período de 1973 a 1983. No mesmo ano, outro estudo conduzido pelos mesmos autores, Ou e Penman (1989b), mostra que as demonstrações financeiras têm poder preditivo, e conclui-se também que tanto as medidas das demonstrações financeiras quanto o índice preço-lucro são capazes de prever o retorno acionário, embora os retornos das ações em ambas as amostras testadas nos dois casos tenham correlação negativa.

Posteriormente, Holthausen e Larcker (1992) desenvolveram um modelo de previsão direta de retornos anormais utilizando 60 dos 68 indicadores apresentados por Ou e Penman (1989a) no período de 1978 a 1988, mostrando que o seu modelo foi capaz de produzir retornos anormais nesse período, contrastando o modelo apresentado por Ou e Penman (1989a).

A partir do artigo de Ou e Penman (1989a), apresentando evidências que corrobora o poder preditivo que as variáveis da análise fundamentalista do retorno das ações, Stober (1992) por meio de uma perspectiva complementar, analisou a capacidade de obtenção de retorno acionário anormal comparando o conjunto de indicadores apresentados por Ou e Penman (1989a) e previsões de analistas do lucro por ação, concluindo que nos casos em que não há consenso na amostra, os indicadores de Ou e Penman (1989a) eram capazes de produzir retornos anormais.

Lev e Thiagarajan (1993) incluíram variáveis macroeconômicas aos indicadores da análise da fundamentalista para encontrar sua significância para retornos anormais e os fundamentos que têm relação com a qualidade ou persistência dos lucros, os quais obtiveram maior relevância entre 1974 e 1988. Abarbanell e Bushee (1997) investigaram as variáveis utilizadas por Lev e Thiagarajan (1993) e concluíram que, em sua maioria, são capazes de auxiliar analistas e outros usuários a avaliar variações futuras nos lucros. Em outro estudo nesta área, Abarbanell e Bushee (1998) concluíram que a estratégia de investimento baseada na análise fundamentalista é capaz de alcançar retornos anormais, com achados consistentes com Ou e Penman (1989a) e Lev e Thiagrajan (1993).

Já Barbee Jr, Mikherki e Raines (1996) encontraram que os indicadores vendas/preço e dívida/patrimônio possuem maior poder de explicação na previsão do retorno das ações que indicadores como book-to-market e tamanho da firma. A pesquisa foi feita para o período de 1979 até 1991.

O uso da informação contábil para a formulação de uma estratégia baseada na análise fundamentalista foi estudada por Piotroski (2000), o índice denominado F-Score foi capaz de separar o que denominou empresas vencedoras das empresas perdedoras, ou seja, as melhores opções de investimento de 1976 a 1996, em uma amostra de empresas com alta razão book-to-market, que segundo o autor, trata-se de empresas negligenciadas pelos analistas, possuindo, dessa maneira, grande potencial de investimento em valor. Mohanram (2005) utiliza a estratégia conhecida G-Score, concluindo que, através de uma estratégia de investimento, utilizando as variáveis da análise fundamentalista, também é capaz de selecionar empresas vencedoras (melhores alternativas de investimento) para empresas com alta razão book-to-market, sendo aqui a possibilidade de investimento em valor a partir de más interpretações de informações contábil-financeiras por parte dos analistas.

Lewellen (2004) verificou o poder preditivo do retorno acionário de indicadores contábil-financeiros como dividend yield, book-to-market e lucro-preço através de regressão linear simples e múltipla. O autor concluiu, então, que o dividend yield foi capaz de prever retornos de mercado, em geral, para o período de 1946-2000 e os índices book-to-market e lucro preço previram retornos para o período de 1963-2000.

Assim, nas pesquisas internacionais, de modo geral, não há consenso no que diz respeito ao poder preditivo dos indicadores da análise das demonstrações financeiras e as variáveis da análise fundamentalista para o retorno acionário. Como afirma em sua pesquisa, Greig (1992), é provável que os índices contábeis variem sistematicamente entre as empresas e ao longo do tempo por razões diferentes da sua associação com mudanças futuras nos lucros contábeis.

No Brasil, Costa Jr. e Neves (2000) verificaram a influência dos seguintes indicadores da análise fundamentalista: valor de mercado, índice preço-lucro e o índice valor de mercado/valor patrimonial em conjunto com o beta das ações, em busca da explicação para a rentabilidade média das ações. Foi utilizado a metodologia SUR na estimação dos coeficientes de regressão múltipla e foi formada carteiras de empresas negociadas na Bovespa entre 1987 a 1996. Assim, essa pesquisa demonstrou uma influência positiva entre o valor de mercado/valor patrimonial e a rentabilidade das ações; outro achado é a influência positiva do beta das ações para a explicação do risco-retorno das empresas contidas na amostra.

Outra comparação entre o modelo de precificação capital asset pricing model (CAPM) e as variáveis da análise fundamentalista foi investigada por Nagano, Merlo e Silva (2003), que desenvolveu um modelo gerado através de uma regressão linear múltipla cujas variáveis independentes foram: beta, relação ativo sobre o valor patrimonial, relação ativo sobre o valor total de mercado, relação dividendos sobre preço, relação fluxo de caixa sobre preço, índice de liquidez em bolsa, valor de mercado da empresa, relação valor patrimonial sobre preço, relação lucro sobre preço, relação vendas sobre preço; para uma amostra de 55 empresas não financeiras negociadas na Bovespa no período de 1995 até 2000, encontrou que as variáveis da análise fundamentalista obtêm maior significância estatística na explicação do retorno das ações que o modelo o já citado modelo CAPM. Ficou constatado pelos autores, então, que as variáveis independentes que possuem a melhor associação com o retorno acionário das empresas são: lucro-preço, valor de mercado, valor patrimonial/preço, liquidez (quanto menor maior o retorno da ação) e o beta; a variável com menor associação é vendas/preço. 
A análise contábil-financeira é de extrema importância para a análise fundamentalista na busca pela relevância dos indicadores contábeis da análise das demonstrações contábeis e a sua relação com o retorno das ações. Nesse sentido, Rangel (2004) estudou as empresas do setor de siderurgia e metalurgia negociadas na Bovespa e a relação dos indicadores contábeis de liquidez, estrutura de capital e rentabilidade e o retorno acionário, concluindo que as empresas com melhores índices contábeis nos anos de 1995, 1996, 1997, 2000 e 2001 também obtiveram os melhores retornos de suas ações. O estudo foi feito de 1995 a 2002.

Bastos, Nakamura, Davi e Rotta (2009) estudaram a relação entre métricas de desempenho, que incluem dados contábeis e de análise de valor, o economic value added® (EVA®), e o retorno acionário para 93 companhias não financeiras de capital aberto no Brasil entre 2001 e 2007. As variáveis independentes da regressão linear múltipla gerada com maior significância em relação ao retorno acionário ajustado pelo mercado foram, respectivamente, fluxo de caixa operacional, retorno sobre o investimento (ROI) e o lucro por ação (LPA). Apesar da importância dos estudos da análise de criação de valor na moderna literatura de finanças, o presente artigo encontrou $\mathrm{R}^{2}$ de apenas 0,0011 para a variável EVA®.

Em outro artigo que verificou a significância estatística dos indicadores da análise das demonstrações financeiras e da análise fundamentalista para companhias negociadas na Bovespa do setor de metalurgia e siderurgia, Ferreira (2010), utilizando regressão linear simples e regressão linear múltipla, conclui que, individualmente, os indicadores com maior associação positiva com o retorno acionário da amostra foi margem bruta, margem líquida e o lucro por ação (LPA). Os indicadores mais significativos na análise do modelo em conjunto foram: participação de capitais de terceiros, imobilização do patrimônio líquido, giro do patrimônio líquido, margem líquida, rentabilidade do ativo, lucro por ação (LPA) e o valor patrimonial por ação. O período estudado neste artigo foi de 2003 a 2007, ou seja, antes da crise do sub-prime.

Galdi e Lopes (2011) investigaram a relação entre o retorno das ações das empresas brasileiras negociadas na BOVESPA e os números contábeis, cuja metodologia aplicada foi a de regressão linear múltipla (dados em painel) para o período de 1997-2008. O número de observações foi de 1678. A partir do modelo, os autores encontraram os seguintes indicadores que explicam o retorno acionário: lucro líquido, variação da rentabilidade, capital investido, variação da oportunidade de crescimento e taxa de desconto.

Tavares e Silva (2012) verificaram se a análise fundamentalista é capaz de segregar as melhores e as piores alternativas de investimento nas empresas não financeiras negociadas na Bolsa de Valores de São Paulo (BOVESPA), nos anos de 2005 a 2007, a partir de 23 indicadores econômico-financeiros tradicionais utilizados por analistas e pesquisadores. Foram aplicados os métodos da regra do qui-quadrado mínimo e da análise discriminante. Apesar da conclusão de que a análise fundamentalista é capaz de separar as empresas vencedoras (melhores alternativas de investimento) das empresas perdedoras (piores alternativas de investimento), poucos indicadores financeiros obtiveram significância estatística. Em 2005, a variável estatisticamente mais significativa foi a margem bruta, já em 2006 os índices foram prazo de recebimento e a razão dívida financeira/patrimônio líquido e para 2007 os indicadores são a razão dívida financeira de curto prazo/dívida financeira total e o grau de alavancagem operacional (GAO).

Para verificar quais indicadores e conjunto de indicadores financeiros e de mercado foram capazes de prever o retorno das ações do índice de mercado Ibovespa, Evrard e Cruz (2016) analisou 16 fatores de retorno ex-ante, referentes à mensuração de cinco famílias de diferentes características dos ativos: risco, liquidez, "barateamento", rentabilidade e desempenho passado. Foram testadas 22 modelos incluindo as variáveis: volatilidade, beta, volume negociação/preço, tendência volume de negociação, retorno sobre o ativo (ROA), retorno sobre o patrimônio líquido (ROE), margem líquida, excesso de retorno 1 mês, excesso de retorno 2 meses, excesso de retorno 6 meses, excesso de retorno 12 meses, lucro/preço, patrimônio líquido/preço, receita/preço, dividendos/preço, valor de mercado. A combinação das 16 variáveis possui um $\mathrm{R}^{2}$ de 0,73 com significância acima de 99\%. Individualmente as variáveis com maior capacidade preditiva foram lucro/preço e valor de mercado.

Malta e Camargos (2016) investigaram as variáveis da análise fundamentalista e da análise dinâmica para verificar seu poder de predição do retorno acionário. A amostra analisada foi composta por 46 ações ordinárias e 21 ações preferenciais de empresas não financeiras negociadas na B3 e componentes do índice IBrX100 a partir de seus dados trimestrais entre 2007 e 2014. As 22 variáveis utilizadas (19 da análise fundamentalista e três da análise dinâmica) foram estudadas num modelo econométrico de regressão linear múltipla. Somente variáveis da análise fundamentalista obtiveram melhor poder de explicação do retorno acionário: participação do capital de terceiros, margem bruta, retorno sobre o ativo (ROA), retorno sobre o patrimônio líquido (ROE), retorno sobre o investimento (ROI), liquidez no mercado, lucro por ação (LPA) e a razão market-to-book.

Mais recentemente, também no Brasil, Fellet (2016) buscou comparar o CAPM com alguns modelos alternativos propostos para precificação de ativos. Para isso, a autora testou 5 variantes do modelo de precificação de ativos de capital: CAPM tradicional, CAPM Global proposto por O’BRIEN et al. (1999), CAPM Local proposto por PEREIRO (2001), APT (ROSS, 1976) e o modelo de 3-Fatores (FAMA; FRENCH, 1993). Neste estudo, foram analisadas 132 ações de empresas brasileiras não financeiras que deram origem a 60 carteiras com ativos combinados de forma aleatória, no período de janeiro de 2010 a dezembro de 2014. Cada carteira possuía 22 ações, que foram ponderadas igualmente. Além das carteiras, os títulos foram analisados individualmente. O modelo de 3-Fatores de Fama e French apresentou resultados superiores aos demais modelos. Nele, a inclusão dos fatores tamanho e book-to-market melhorou o poder explicativo em relação ao CAPM tradicional, enquanto a inclusão de variáveis macroeconômicas proporcionou um melhor desempenho do modelo APT em comparação ao CAPM. A versão original do modelo CAPM apresentou-se adequado na precificação 
dos ativos no Brasil. Particularmente, o beta referente ao prêmio de mercado apresentou-se significativo em todos os testes realizados. No entanto, os modelos CAPM Global e CAPM Local (com inclusão do risco país) não se mostraram significativos, mostrando que não há um consenso sobre esse assunto também no Brasil.

Conforme apontam as conclusões dos principais estudos apresentados nessa revisão, não foi observado consenso na literatura nacional em relação a um indicador ou conjunto de indicadores contábil-financeiros que possuem poder preditivo do retorno acionário, embora o indicador lucro por ação tenha apresentado boa associação com o retorno das ações.

Assim, o modelo econométrico que será apresentado nessa pesquisa testa inclui a variável independente de interesse fluxo de caixa livre/preço (FCF/P) em conjunto com outros indicadores tradicionais da análise fundamentalista e da análise das demonstrações financeiras. Como é amplamente utilizado o modelo de fluxo de caixa descontado no mercado para avaliação de empresas, o presente trabalho irá verificar como a inclusão desta variável influencia a significância estatística do modelo e o poder preditivo do retorno acionário em relação aos modelos anteriormente pesquisados.

\section{MÉTODO DE PESQUISA}

\subsection{HIPÓTESES}

A partir do que foi observado na literatura, a variável fluxo de caixa livre é amplamente utilizada em modelos de avaliação de empresas pelo método do fluxo de caixa descontado (DAMODARAN, 1997; MARTINS et al, 2001; COPELAND, KOLLER, MURRIN, 2002; PÓVOA, 2012). Portanto, a hipótese dessa pesquisa é de que a variável fluxo de caixa livre/preço (FCF/P) tenha uma correlação positiva com o retorno acionário e significância estatística para previsão da variável dependente no modelo.

\subsection{VARIÁVEIS}

\subsubsection{Modelo}

O modelo econométrico utilizado será, conforme a equação 1, demonstrado abaixo:

$$
\begin{gathered}
\mathrm{RET}_{\mathrm{it}}=\beta_{0}+\beta_{1} F C F / \mathrm{P}_{\mathrm{it}}+\beta_{2} \mathrm{LIQ}_{\mathrm{it}}+\beta_{3} \mathrm{END}_{\mathrm{it}}+\beta_{4} R O A_{\mathrm{it}}+\beta_{5} \mathrm{MB}_{\mathrm{it}}+\beta_{6} \mathrm{~L} / \mathrm{P}_{\mathrm{it}}+\beta_{7} D Y_{\mathrm{it}}+ \\
\beta_{8} \mathrm{~V} / \mathrm{P}_{\mathrm{it}}+\beta_{10} E B I T D A / \mathrm{P}+\beta_{9} B M_{\mathrm{it}}+\alpha_{\mathrm{i}}+\varepsilon_{\mathrm{it}}
\end{gathered}
$$

Onde: $\mathrm{RET}$ = retorno acionário; FCF $/ \mathrm{P}$ = fluxo de caixa livre/preço; LIQ = liquidez corrente; END = endividamento; ROA = retorno sobre o ativo; $\mathrm{MB}=$ margem bruta; $\mathrm{L} / \mathrm{P}=$ lucro/preço; $\mathrm{DY}=$ dividend yield $; \mathrm{V} / \mathrm{P}=$ vendas $/$ preço; $\mathrm{EBITDA} / \mathrm{P}=$ lucro antes de juros, imposto de renda, depreciação e amortização (earnings before interest, taxes, depreciation and amortization)/preço; $\mathrm{BM}=$ book-to-market. No modelo, ainda, $\mathrm{i}=$ ação, $\mathrm{t}=$ trimestre, $\alpha \mathrm{i}=$ efeitos fixos individuais e $\varepsilon$ it $=$ erro estocástico.

\subsubsection{Retorno acionário (RET)}

A variável dependente utilizada no modelo de regressão na pesquisa é o retorno acionário (RET). Conforme a literatura empírica analisada, o retorno acionário (RET) já foi amplamente investigado e, em geral, foi possível observar que um conjunto de índices contábeis e da análise fundamentalista obteve significância estatística para prever o retorno acionário (RET) num determinado período de tempo.

A equação 2 abaixo demonstra o cálculo do retorno acionário (RET):

$$
\text { RET }=\frac{\text { Preço da ação }_{i t}-\text { Preço da ação }_{i t-1}}{\text { Preço da ação }}
$$

\subsubsection{Fluxo de caixa livre/preço (FCF/P)}

O fluxo de caixa livre, também conhecido pelo termo em inglês free cash flow (FCF), de acordo com a principal literatura já citada em avaliação de empresas, é amplamente utilizado no mercado para estimar o valor de uma empresa em técnica conhecida como o fluxo de caixa descontado (FCD). No presente trabalho, utiliza-se o índice de mercado fluxo de caixa livre/preço (FCF/P) como a variável explicativa de interesse, já que há carência na literatura em pesquisa empírica no mercado de capitais. Como é esperada uma relação direta entre o fluxo de caixa livre e o valor de uma empresa, supõe-se que o sinal desse indicador seja positivo. 
O índice fluxo de caixa livre/preço (FCF/P) é calculado conforme a equação 3 abaixo:

$$
\mathrm{FCF} / \mathrm{P}=\frac{\text { (Caixa gerado por operação por ação-Capex por ação) }}{\text { Cotação da ação não ajustada para proventos }}
$$

Onde, de acordo com a fórmula 4:

$$
\text { Capex }=-1 \times \text { Compra líquida de ativo permanente }
$$

Se compra líquida de ativo permanente é zero, então, aplica-se a equação 5 :

$$
\text { Capex }=\text { Aplicação no ativo permanente }- \text { venda de ativos fixos }
$$

Onde: Capex $=$ Capital expenditures.

\subsubsection{Liquidez corrente (LIQ)}

O índice de liquidez utilizado como variável independente é o de liquidez corrente (LIQ), pois, para Iudícibus (1998), trata-se do melhor indicador da situação de liquidez de uma empresa. Diversos trabalhos utilizaram indicadores de liquidez em modelos relacionados de previsão do retorno acionário a fim de testar sua a significância estatística (NAGANO, MERLO, 2003; RANGEL 2004, FERREIRA 2010, MALTA, CAMARGOS; 2016) até por tratar-se de importante variável da análise fundamentalista. Nagano e Merlo (2003) revelaram que a liquidez possui significância estatística com retorno acionário.

De acordo com Assaf Neto (2010) "quanto maior a liquidez corrente, mais alta se apresenta a capacidade da empresa em financiar suas necessidades de capital de giro”. Assim, é esperado sinal positivo para esse indicador.

A equação 6 demonstra a fórmula da liquidez corrente (LIQ):

$$
\text { LIQ }=\frac{\text { Ativo circulante }}{\text { Passivo circulante }}
$$

\subsubsection{Endividamento (END)}

Em pesquisas anteriores, foi demonstrado que indicadores de endividamento possuem significância estatística (FERREIRA, 2010; TAVARES, SILVA, 2012; MALTA, CAMARGOS, 2016) . O sinal esperado para essa variável independente pode ser tanto positivo como negativo, já que, apesar de que muitas empresas que vão à falência apresentam uma relação capital de terceiros/capital próprio grande no longo prazo, ainda que isso não signifique que necessariamente elas irão à falência. Para empresas com necessidade de expanão, às vezes uma combinação adequada de capital de terceitos e capital próprio é a melhor alternativa. (IUDÍCIBUS, 1998).

A equação 7 descreve sua fórmula abaixo:

$$
\text { END }=\frac{\text { Dívida bruta }}{\text { Patrimônio líquido }}
$$

\subsubsection{Retorno sobre o ativo (ROA)}

O indicador de rentabilidade a ser testado no modelo como variável independente é o retorno sobre o ativo (ROA), que constitui um dos mais importantes indicadores de rentabilidade de uma empresa (ASSAF NETO, 2012). Malta e Camargos (2016) demonstraram que o indicador retorno sobre o ativo (ROA) possui poder de explicação do retorno acionário e Ferreira (2010) demonstra que o retorno sobre o ativo (ROA) tem significância estatística para o retorno acionário.

O sinal esperado é positivo.

Sua fórmula está demonstrada na equação 8 abaixo:

$$
\mathrm{ROA}=\frac{\text { Lucro líquido+participação acionária minoritária }}{\text { Ativo total }}
$$




\subsubsection{Margem bruta (MB)}

Trata-se de um indicador de rentabilidade, Malta e Camargos (2016) evidenciaram que a margem bruta (MB) possui poder de explicação do retorno acionário. Com essa variável independente se busca verificar a eficiência da empresa em relação aos custos das vendas. Ferreira (2010) destaca que o a margem bruta (MB) possui correlação positiva com o retorno acionário. $O$ sinal esperado, portanto, é positivo. A fórmula se encontra abaixo na equação 9:

$$
\mathrm{MB}=\frac{\text { Lucro bruto }}{\text { Receita líquida operacional }}
$$

\subsubsection{Lucro/preço (L/P)}

Apresenta-se aqui um dos principais indicadores de mercado utilizado como variável independente na equação gerada. Seu uso também é amplo na pesquisa empírica no mercado de capitais nacional e internacional (LEWELLEN, 2002; NAGANO, MERLO, SILVA, 2003; EVRARD, CRUZ, 2016) geralmente encontrando alto poder explicativo individual para a previsão do retorno acionário. Dessa maneira, o sinal esperado no modelo é positivo.

A equação 10 demonstra o cálculo dessa variável:

$$
\mathrm{L} / \mathrm{P}=\frac{\text { Lucro líquido (por ação) }}{\text { Cotação da ação não ajustada para proventos }}
$$

\subsubsection{Dividend yield (DY)}

Para Assaf Neto (2014) essa variável "indica a remuneração por dividendos do acionista realizada sobre o capital investido (valor pago pela ação)". Lewellen (2004) encontrou bom poder de predição do retorno acionário dessa variável independente. O sinal esperado é positivo.

Sua fórmula é demonstrada pela equação 11 abaixo:

$$
D Y=\frac{\text { Dividendo pago por ação }}{\text { Cotação da ação não ajustada para proventos }}
$$

\subsubsection{Vendas/preço (V/P)}

Barbee Jr, Mukherji e Raines (1996) destacaram que há um alto poder explicativo da variável vendas/preço para a explicação da previsão do retorno acionário. O sinal esperado para essa variável independente é positivo.

Abaixo, segue a equação 12 com a sua fórmula:

$$
\mathrm{V} / \mathrm{P}=\frac{\text { Receita líquida operacional por ação }}{\text { Cotação da ação não ajustada para proventos }}
$$

\subsubsection{EBITDA/preço (EBITDA/P)}

Segundo Assaf Neto (2014) o EBITDA (earnings before interest, taxes, depreciation and amortization), ou, em português, LAJIDA (lucro antes de juros, imposto de renda, depreciação, amortização e exaustão) é uma medida de geração de caixa operacional disponível para todos os proprietários de capital. Na presente pesquisa, foi incluída no modelo a variável independente o índice de mercado EBITDA/preço. Espera-se que o seu sinal seja positivo.

Seu cálculo é detalhado abaixo pela equação 13:

$$
\text { EBITDA/P }=\frac{\text { EBITDA por ação }}{\text { Cotação da ação não ajustada para proventos }}
$$

\section{Book-to-market (BM)}

Outro indicador amplamente pesquisado na literatura empírica no mercado de capitais (PIOTROSKI, 2000; LEWELLEN, 2002; MONHANRAM; 2005), aqui será utilizada como variável independente. Piotroski (2000) destaca que para as 
empresas com alta relação book-to-market, os indicadores contábeis e da análise fundamentalista tendem a possuir maior poder preditivo do retorno acionário, um dos motivos é a negligência dos analistas e outros usuários das demonstrações contábeis dessas empresas. Contudo, Monhanram (2005) encontrou que a estratégia de investimento baseada na análise fundamentalista, denominada G-Score, seleciona melhores alternativas de investimento também para empresas com alta relação book-to-market. Em relação à utilização do book-to-market (BM) como variável independente para a predição de retorno acionário, Lewellen (2004) evidenciou um alto poder explicativo para esse indicador. É esperado o sinal positivo para essa variável.

A fórmula se encontra abaixo na equação 14:

$$
\mathrm{BM}=\frac{\text { Valor patrimonial da ação }}{\text { Cotação da ação não ajustada para proventos }}
$$

\subsection{DEFINIÇÃO DA AMOSTRA}

A amostra será a base de dados do Economática®, para as empresas não-financeiras de capital aberto negociadas no mercado brasileiro, que têm dados disponível conforme as variáveis definidas para o estudo. A amostra contém 245 ações de classe ON e 157 ações de outras classes.

\subsection{COLETA E ANÁLISE DE DADOS}

Inicialmente é feita a coleta dos dados respectivos às informações trimestrais das demonstrações financeiras disponíveis no banco de dados do software Economática ${ }^{\circledR}$ para as empresas definidas na amostra no período de 2008 a 2016. Neste estudo, as análises iniciaram-se no ano de 2008 por dois motivos: (1) com o intuito de se analisar o período compreendido após a deflagração da crise financeira de 2008, que alterou significativamente tanto os preços das ações quanto as volatilidades dos títulos negociados no mercado acionário comparativamente aos anos anteriores à crise de 2008 e (2) em função da promulgação da Lei 11.638/07, que introduziu a partir de 2008 as normas internacionais de contabilidade no Brasil. Assim, entende-se que análises anteriores a esse período poderiam distorcer os modelos aplicados nesta pesquisa. O software utilizado para estimação do modelo proposto no trabalho foi o Stata® 14.9.

A metodologia utilizada para a estimação do modelo é a de dados em painel que possui vantagens que melhoram a análise empírica em relação ao uso do cross-section ou séries temporais (GUJARATI, 2003). Para determinar qual a melhor estimação que se ajusta ao modelo proposto entre as abordagens POLS robusto, efeito fixo robusto e o efeito aleatório robusto, serão utilizados os testes de Chow, Breusch-Pagan e Hausman robusto.

A respeito dos pressupostos básicos do modelo de regressão linear múltipla, foi testado se os resíduos possuem distribuição homocedástica ou não, por meio do teste de heterocedasticidade de White. Quanto à multicolinearidade, foi utilizado o teste VIF - Variance Inflation Factor, além de observar a matriz de correlação das variáveis.

A fim de diagnosticar se o modelo estimado possui problemas de autocorrelação dos resíduos, foi utilizado o teste de autocorrelação serial de Wooldridge para dados em painéis, sendo indicado que o modelo não possui este problema. Entretanto, como foram coletados dados com periodicidade trimestral foi possível criar uma base de dados com painel longo, possibilitando a estimação do modelo por meio de um painel dinâmico estimado por GMM (generalized method of moments) de acordo com o método desenvolvido por Arellano e Bond (1991). Este método lida com possíveis problemas de endogeneidade e estima os parâmetros do modelo de forma consistente. Ainda, foi possível estimar a variável explicativa de interesse fluxo de caixa livre/preço (FCF/P) defasada em t-1, t-2 e t-3 períodos, e verificar a relação das defasagens com a variável dependente retorno acionário (RET). Desse modo, será testada a significância estatística para a variável explicativa de interesse também em períodos defasados (t-1, t-2 e t-3).

\section{RESULTADOS E ANÁLISES}

\subsection{ESTATÍSTICA DESCRITIVA}

A Tabela 1 apresenta a estatística descritiva dos indicadores da análise fundamentalista em base trimestral das ações que foram utilizados como variáveis do modelo no período de 2008 até 2016.

Tabela 1 - Estatística descritiva dos índices da análise fundamentalista trimestrais das ações entre 2008 e 2016

\begin{tabular}{l|c|c|c|c}
\hline Variáveis & Média & Mediana & Desvio Padrão & Observações \\
\hline RET & 0,1675 & 0,1190 & 0,1752 & 8750 \\
FCF/P & 0,0801 & 0,0311 & 0,2350 & 8773 \\
LIQ & 1,9604 & 1,6173 & 1,4260 & 11840
\end{tabular}




\begin{tabular}{l|c|c|c|c}
\hline Variáveis & Média & Mediana & Desvio Padrão & Observações \\
\hline END & 0,8158 & 0,5838 & 1,0265 & 11781 \\
ROA & 0,0236 & 0,0141 & 0,0679 & 11734 \\
MB & 0,3540 & 0,3041 & 0,2268 & 11280 \\
L/P & 0,0500 & 0,0207 & 0,1477 & 9574 \\
DY & 0,0096 & 0,0000 & 0,0253 & 10210 \\
V/P & 0,4640 & 0,2579 & 0,7155 & 9404 \\
EBITDA/P & 0,0714 & 0,0448 & 0,1219 & 8709 \\
BM & 1,0958 & 0,7343 & 1,2124 & 9736 \\
\hline
\end{tabular}

Legenda: RET - Retorno acionário, FCF/P - Fluxo de caixa livre/preço, LIQ - Liquidez corrente, END - Endividamento, ROA - Retorno sobre o ativo, MB - Margem bruta, L/P - Lucro/preço, DY - Dividend yield, V/P - Vendas/preço, EBITDA/P - EBITDA/preço (EBITDA - earnings before interest, taxes, depreciation and amortization), BM - Book-to-market

Fonte: Elaboração própria com base nos dados do Economática®

Como pode ser visualizado na tabela 1, o retorno acionário trimestral das ações para o período pesquisado foi de 0,1675 ou $16,75 \%$, enquanto a mediana foi de $11,90 \%$. O valor do desvio padrão da variável atingiu $17,25 \%$. Para o mesmo período, a média da variável explicativa de interesse (FCF/P) foi de 8,01\%, enquanto a mediana atingiu 3,11\% e o desvio-padrão foi 23,50\%. Pode ser observado para o período total, que em média, em relação ao preço das ações das companhias, 8,01\% representam fluxos de caixa livre para as companhias.

Em relação as demais variáveis explicativas do modelo, pode ser observado uma média de 1,96 para a variável liquidez corrente, ou seja, para cada 1 valor total de passivos circulante, as companhias possuem em média 1,96 valores totais de ativos circulante. A mediana da variável foi de 1,61, enquanto o desvio-padrão foi de 1,42. Para a variável endividamento pode ser observado uma média de 81,58\%, mediana de 58,38\% e desvio-padrão de 102,65\%. A variável ROA apresentou uma média de 2,36\%, mediana de 1,41\% e desvio-padrão de 6,79\%. A variável margem bruta (MB) apresentou uma média de 35,40\%, mediana de 30,41 e desvio-padrão de 22,68\%. A variável L/P apresentou uma média de $5 \%$, ou seja, durante o período em análise as companhias demonstraram um percentual médio de $5 \%$ de seus lucros em relação ao preço de suas ações. A mediana da variável atingiu um valor menor em comparação à média, de $2,07 \%$ e o desvio-padrão $14,77 \%$. O dividend-yield atingiu um valor médio de $0,96 \%$, mediana de $0,00 \%$ e desvio-padrão de $2,53 \%$. Para a variável V/P pode ser observado um valor médio de 46,4\%, mediana de $25,79 \%$ e desvio-padrão de $71,55 \%$. A variável EBITDA/P atingiu uma média de 7,14\%, mediana de 4,48\% e desvio-padrão de 12,19\%. E por fim, a variável book-to-market atingiu um valor médio de 1,09, mediana de 0,73 e desvio-padrão de 1,21.

Na subseção abaixo estão evidenciadas as estimações do modelo proposto pelo trabalho pela metodologia de dados em painel.

4.2. ESTIMAÇÕES POR DADOS EM PAINEL PELOS MÉTODOS POLS, EFEITO FIXO ROBUSTO E EFEITO ALEATÓRIO ROBUSTO

A Tabela 2 apresenta os resultados para as três estimações utilizadas em dados em painel robusto.

Tabela 2 - Análise da significância estatística do modelo para as três estimações em POLS robusto, efeito fixo robusto e efeito aleatório robusto

\begin{tabular}{l|c|c|c|c|c|c|c|c|c}
\hline $\begin{array}{l}\text { Variável } \\
\text { Dependente }\end{array}$ & \multicolumn{7}{|c}{ RET } \\
\hline $\begin{array}{l}\text { Variáveis } \\
\text { independentes }\end{array}$ & Coef. & Est. t & p-valor & Coef. & Est. t & p-valor & Coef. & Est. Z & p-valor \\
\hline FCFP & 0,047 & $2,34^{\star *}$ & 0,019 & 0,007 & 0,50 & 0,617 & 0,017 & 1,18 & 0,239 \\
LIQ & 0,004 & $2,09^{\star *}$ & 0,037 & 0,004 & 1,23 & 0,219 & 0,003 & 1,18 & 0,236 \\
END & 0,007 & $1,77^{\star}$ & 0,077 & 0,007 & 1,16 & 0,246 & 0,007 & 1,34 & 0,181 \\
ROA & 0,117 & 1,06 & 0,290 & 0,116 & 0,97 & 0,333 & 0,122 & 1,05 & 0,295 \\
MB & $-0,028$ & $-1,81^{*}$ & 0,071 & 0,004 & 0,18 & 0,858 & $-0,006$ & $-0,41$ & 0,683
\end{tabular}




\begin{tabular}{|c|c|c|c|c|c|c|c|c|c|}
\hline \multirow{2}{*}{$\begin{array}{l}\text { Variável } \\
\text { Dependente }\end{array}$} & \multicolumn{9}{|c|}{ RET } \\
\hline & Coef. & Est. $t$ & p-valor & Coef. & Est. $t$ & p-valor & Coef. & Est. Z & p-valor \\
\hline LP & 0,089 & $2,62^{\star \star \star}$ & 0,009 & 0,060 & $1,72^{\star}$ & 0,087 & 0,066 & $1,92^{\star}$ & 0,055 \\
\hline DY & $-0,254$ & $-3,28^{\star \star \star}$ & 0,001 & $-0,009$ & $-0,13$ & 0,897 & $-0,047$ & $-0,64$ & 0,520 \\
\hline VP & 0,012 & $1,95^{\star}$ & 0,052 & 0,010 & 1,28 & 0,199 & 0,011 & 1,63 & 0,102 \\
\hline EBITDAP & 0,032 & 1,21 & 0,227 & 0,029 & 1,04 & 0,301 & 0,030 & 1,08 & 0,278 \\
\hline BM & 0,004 & 1,25 & 0,213 & 0,010 & $2,35^{\star \star}$ & 0,019 & 0,007 & $1,96^{\star \star}$ & 0,049 \\
\hline Constante & 0,138 & $13,63^{\star \star \star}$ & 0,000 & 0,123 & $8,60 * \star \star$ & 0,000 & 0,136 & $11,10^{\star \star \star}$ & 0,000 \\
\hline Modelos & \multicolumn{3}{|c|}{1} & \multicolumn{3}{|c|}{2} & \multicolumn{3}{|c|}{3} \\
\hline $\mathbf{N}$ & \multicolumn{3}{|c|}{6906} & \multicolumn{3}{|c|}{6906} & \multicolumn{3}{|c|}{6.906} \\
\hline Prob > Chi2: & \multicolumn{3}{|c|}{ N/A } & \multicolumn{3}{|c|}{ N/A } & \multicolumn{3}{|c|}{0,000} \\
\hline Prob > F & \multicolumn{3}{|c|}{0,000} & \multicolumn{3}{|c|}{0,000} & \multicolumn{3}{|c|}{ N/A } \\
\hline $\mathbf{R}^{2}:$ & \multicolumn{3}{|c|}{0,0344} & \multicolumn{3}{|c|}{0,0287} & \multicolumn{3}{|c|}{0,0319} \\
\hline Estimação: & \multicolumn{3}{|c|}{ POLS Robusto } & \multicolumn{3}{|c|}{ Efeito Fixo Robusto } & \multicolumn{3}{|c|}{ Efeito Aleatório Robusto } \\
\hline VIF Médio & \multicolumn{9}{|c|}{1,49} \\
\hline \multicolumn{10}{|c|}{ Teste de Autocorrelação Serial } \\
\hline F estatístico & \multicolumn{9}{|c|}{1,016} \\
\hline Prob > F: & \multicolumn{9}{|c|}{0,3142} \\
\hline \multicolumn{10}{|c|}{ Teste de Chow } \\
\hline F estatístico & \multicolumn{9}{|c|}{$3,01^{\star \star \star}$} \\
\hline Prob > F: & \multicolumn{9}{|c|}{0,0000} \\
\hline \multicolumn{10}{|c|}{ Teste de Breusch-Pagan } \\
\hline Chi $^{2}:$ & \multicolumn{9}{|c|}{$249,73^{\star \star \star}$} \\
\hline Prob > Chi²: & \multicolumn{9}{|c|}{0,0000} \\
\hline \multicolumn{10}{|c|}{ Teste de Hausman robusto } \\
\hline Chi': & & & & & 8,100 & & & & \\
\hline Prob > Chi ${ }^{2}$ : & & & & & 0,6189 & & & & \\
\hline
\end{tabular}

Variáveis: RET - retorno acionário, FCFP - fluxo de caixa livre/preço, LIQ - liquidez corrente, END - endividamento, ROA retorno sobre o ativo, MB - margem bruta, LP - lucro-preço, DY - dividend yield, VP - vendas/preço, EBITDAP - EBITDA/preço, BM - book-to-market, N/A: Não Aplicável. Rejeição da hipótese nula: ***nível de significância 1\%; **nível de significância 5\%; *nível de significância 10\%.

Fonte: Elaboração própria

Os modelos foram estimados com a matriz de variância e covariância robusta, pois o teste de White, que verifica a hipótese de homocedasticidade dos resíduos, indicou a rejeição da hipótese nula do teste a 1\% de significância. É possível observar que o VIF médio foi 1,49, indicando que não há problemas de multicolinearidade nos modelos, pois segundo Fávero (2013), um VIF médio abaixo de 5 sugere que as estimações não sofrem problemas de multicolinearidade. Ainda, pode ser observado no teste de autocorrelação serial de Wooldridge para dados em painéis, a não rejeição da hipótese de que o modelo estimado não sofre problemas de autocorrelação serial a um nível de $1 \%$ de significância de $1 \%$.

Os resultados dos testes de Chow, de Breusch-Pagan e de Hausman robusto indicaram que a melhor estimação seria por efeito aleatório robusto, entretanto, de acordo com a Tabela 2, é possível verificar que a variável explicativa de interesse fluxo de caixa livre/preço $(\mathrm{FCF} / \mathrm{P})$ não foi estatisticamente significativa pela estimação em efeito aleatório 
robusto, nem por efeito fixo robusto. Isso pode ocorrer devido à baixa variação das variáveis - variação within - ao longo do tempo. Essa baixa variação, ou até mesmo em alguns casos repetição de valores ao longo de dois ou mais períodos, pode ser interpretado pelo método de efeitos fixos ou aleatórios como um efeito fixo às empresas, o que acarretaria em perda de eficiência na estimação dos parâmetros. Portanto, independente dos testes específicos da literatura optou-se na análise do modelo estimado pelo método POLS ao analisar a estimação do modelo pela metodologia de dados em painel.

Não obstante, na próxima subseção foi estimado também o modelo também pelo método de Arellano e Bond (1991). A metodologia do painel dinâmico é estimada por um GMM (generalized method of moments) e possui benefícios ao lidar com problemas de endogeneidade, assegurando também a consistência na estimação dos parâmetros. Assim, a análise de resultados do modelo será por meio do método POLS e pelo método do painel dinâmico, este último presente na próxima subseção.

A variável explicativa de interesse fluxo de caixa livre/preço (FCF/P) obteve sinal positivo e significante a um nível de $5 \%$, indo ao encontro do arcabouço teórico apresentado na revisão de literatura, e corroborando para que este índice de mercado venha a se tornar útil ao investidor ao fazer projeções futuras do valor de uma empresa. Esta relação é construída a partir da ampla utilização deste indicador nos modelos do mercado para avaliação do valor das companhias. Dessa forma, há indícios de que um aumento na relação do fluxo de caixa livre sobre o preço das ações, levam a um maior retorno acionário às companhias presentes na amostra do estudo. Assim, a relação estudada se faz importante pela possibilidade de ser utilizada por investidores na realização de análises fundamentalistas.

A variável liquidez corrente (LIQ) foi estatisticamente significante a um nível de $5 \%$, semelhante ao encontrado por Malta e Camargos (2016). De acordo com a teoria apresentada, a relação pode ser explicada pela importância que o indicador possui para o financiamento das necessidades de capital de giro das companhias (ASSAF NETO, 2010). Para a variável endividamento (END), foi encontrado sinal positivo e estatisticamente significante a um nível de $10 \%$. Esta relação fornece indícios que um aumento no nível de endividamento das companhias, leva a um aumento em seus retornos acionários. Essa relação pode ser atribuída à percepção dos investidores, analistas e outros usuários das demonstrações financeiras, na qual o endividamento pode ser uma melhor alternativa para a estruturação do capital das empresas no período analisado, possivelmente para expansão ou financiamento de oportunidades de investimentos.

O retorno sobre o ativo (ROA) não foi estatisticamente significativo para a predição do retorno acionário (RET), ao contrário do que foi indicado pela revisão de literatura. Assim, não há evidências estatísticas que apontem que investidores, analistas e outros usuários das demonstrações contábil-financeiras utilizaram esse índice para tomar decisões quanto ao nível de rentabilidade das organizações (ASSAF NETO, 2012), e, consequentemente, demandaram as ações dessas companhias, aumentando seus retornos acionários. Já em relação a variável margem bruta (MB), foi encontrado relação negativa e estatisticamente significante, sinal inverso ao indicado pela revisão de literatura.

A variável lucro/preço (L/P) apresentou relação positiva e estatisticamente significante. Essa relação pode ser construída a partir da percepção dos stakeholders das companhias sobre a relação dos seus lucros e o preço de suas ações. Sendo assim, investidores, analistas e outros agentes identificam lucros como maiores retornos futuros para seus portfólios, e, portanto, demandam essas ações. Esses resultados vão de encontra aos trabalhos de Lewellen (2004), Nagano, Merlo e Silva (2003) e Evrard e Cruz (2016).

Pode ser observado para a variável dividend yield (DY) coeficiente negativo e estatisticamente significante a um nível de $1 \%$. A relação negativa não está de acordo com trabalho de Lewellen (2004), entretanto pode ser pressuposto que uma alta distribuição de dividendos sinalize ao mercado que a companhia não possui mais oportunidades de crescimento, o que levaria a uma redução na demanda de suas ações, resultando na relação negativa encontrada. Ainda referente ao trabalho de Lewellen (2004), não foram encontrados coeficientes estatisticamente significantes para a variável EBIT$\mathrm{DA}$ /preço e a variável book-to-market (BM). Já para a variável vendas/preço (V/P) foi observado relação positiva e estaticamente significante semelhante aos trabalhos de Nagano, Merlo e Silva (2003) e Barbee Jr, Mukherji e Raines (1996).

\subsection{ESTIMAÇÃO POR DADOS EM PAINEL DINÂMICO}

O pressuposto inicial de que as estimações possuíssem ausência de autocorrelação serial foi confirmado pela estatística do teste de autocorrelação serial presente na tabela 2. Entretanto, conforme já foi estudado por trabalhos como Famá, Oda e Yoshinaga (2003) e Famá, Cioffi e Coelho (2008), o mercado acionário brasileiro possui anomalias quanto à hipótese de mercado eficiente proposta por Malkiel e Fama (1970) e Fama (1991), principalmente anomalias voltadas para avaliação das ações e para previsões de preços acionários futuros.

Dessa maneira, uma análise defasada do impacto da variável FCF/P nos preços das ações justifica-se em função de eventuais anomalias de mercado e assimetrias informacionais existentes no mercado de ações brasileiro que podem fazer com que as informações disponíveis não sejam imediatamente incorporadas às cotações dos títulos, sendo plausível pressupor que os indicadores de análise fundamentalista referentes a um dado período são assimilados por investidores, analistas e outros usuários das demonstrações financeiras, em períodos posteriores.

Assim, com o objetivo de analisar se existem relações defasadas da variável explicativa de interesse, fluxo de caixa livre/preço da ação, sobre o retorno acionário das companhias, foi desenvolvido nesta subseção a estimação do modelo de dados em painel dinâmico estimado por um GMM (generalized method of moments), desenvolvido por Arellano e Bond (1991). Cabe ressaltar que os resultados apresentados por esse método são consistentes e lidam com possíveis problemas de endogeneidade. Os resultados são apresentados na Tabela 3. 
Tabela 3 - Análise da significância estatística do modelo para a estimação por dados em painel dinâmico com variável explicativa de interesse defasada

\begin{tabular}{|c|c|c|c|}
\hline Variável Dependente & \multicolumn{3}{|c|}{ RET } \\
\hline Variáveis independentes & Coef. & Est. Z & p-valor \\
\hline RET (-1) & $-0,0036$ & $-0,12$ & 0,9050 \\
\hline RET (-2) & $-0,0130$ & $-0,45$ & 0,6530 \\
\hline RET (-3) & 0,0523 & $2,25^{\star \star}$ & 0,0250 \\
\hline FCFP & $-0,0239$ & $-0,69$ & 0,4920 \\
\hline FCFP $(-1)$ & 0,1021 & $2,77^{\star \star \star}$ & 0,0060 \\
\hline FCFP (-2) & 0,0654 & 1,58 & 0,1150 \\
\hline FCFP $(-3)$ & 0,0719 & $2,47^{\star *}$ & 0,0130 \\
\hline LIQ & $-0,0022$ & $-0,33$ & 0,7390 \\
\hline END & 0,0118 & 0,82 & 0,4110 \\
\hline ROA & $-0,1183$ & $-0,58$ & 0,5640 \\
\hline MB & 0,0227 & 0,63 & 0,5290 \\
\hline LP & 0,0774 & 1,42 & 0,1550 \\
\hline DY & $-0,0153$ & $-0,18$ & 0,8540 \\
\hline VP & $-0,0202$ & $-1,26$ & 0,2080 \\
\hline EBITDAP & $-0,0209$ & $-0,54$ & 0,5860 \\
\hline BM & 0,0060 & 0,34 & 0,7370 \\
\hline Constante & 0,1239 & 4,63 & 0,0000 \\
\hline $\mathbf{N}$ & & 5.405 & \\
\hline $\mathrm{Chi}^{2}$ & & $42,23^{* * *}$ & \\
\hline Prob > Chi ${ }^{2}$ : & & 0,0000 & \\
\hline
\end{tabular}

Variáveis: RET - retorno acionário, FCFP - fluxo de caixa livre/preço, LIQ - liquidez corrente, END - endividamento, ROA - retorno sobre o ativo, MB - margem bruta, LP - lucro-preço, DY - dividend yield, VP - vendas/preço, EBITDAP - EBITDA/preço, BM

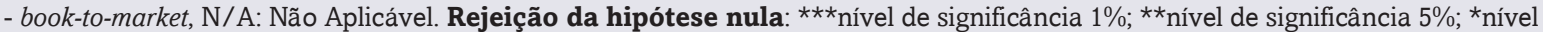
de significância $10 \%$.

Legenda: Elaboração própria

Pela Tabela 3, observam-se relações defasadas e estatisticamente significantes com sinais positivos, em 1 e 3 períodos, entre a variável de interesse (FCF/P) e a variável retorno acionário (RET) em período corrente. Portanto, conforme o esperado, um aumento no indicador de mercado fluxo de caixa livre/preço causa um impacto temporal positivo no retorno acionário (RET) do trimestre seguinte e no terceiro trimestre seguinte. Isso deve ocorrer, pois há uma defasagem temporal tanto para que a divulgação das informações referentes à análise fundamentalista, quanto para que essas informações sejam de conhecimento geral dos investidores, analistas e outros usuários das demonstrações contábil-financeiras.

\section{CONCLUSÃO}

A presente pesquisa teve como objetivo investigar se a variável da análise fundamentalista fluxo de caixa livre/ preço (FCF/P) é capaz de prever o retorno acionário (RET), assim como outras variáveis da análise fundamentalista. Os resultados das estimações realizadas no estudo apontaram que existe relação positiva entre o fluxo de caixa livre/preço (FCF/P) e o retorno acionário (RET).

Para a estimação do modelo foram utilizadas duas abordagens. A primeira por meio da metodologia de dados em painel, estimando o modelo por POLS, efeitos fixos e efeitos aleatórios. Posteriormente, com o objetivo de investigar as 
relações defasadas da variável de interesse fluxo de caixa livre/preço (FCF/P) foi utilizado o método de painel dinâmico estimado por um GMM.

A partir dos testes inerentes a literatura de dados em painel, verificou-se que o modelo que mais se adequa aos dados é o modelo estimado com efeitos aleatórios robustos. De acordo com essa estimação, índices da análise fundamentalista que foram estatisticamente significativos para a predição do retorno acionário (RET) foram o lucro/preço (L/P) e o book-to-market (BM), assim como uma relação positiva entre ambos e a variável dependente, conclusão semelhante à encontrada por Lewellen (2004). Diferentemente da suposição teórica, entretanto, somente os indicadores margem bruta (MB) e dividend yield (DY) obtiveram sinal negativo.

O fato de poucos indicadores serem estatisticamente significativos para prever o retorno acionário (RET) é condizente com a literatura empírica em contabilidade no mercado de capitais nacional. Porém, as variáveis da base de dados apresentam baixa variação within, ou até mesmo repetições de valores ao longo de dois ou mais períodos, visto que não apresentam variação considerável de um trimestre para outro, o que pode levar na interpretação da estimação dos parâmetros como um efeito fixo às empresas, quando na verdade não o são, acarretando em perda na eficiência dos estimadores. Dessa forma, o trabalho optou em analisar os coeficientes estimados de acordo com o método POLS que demonstra melhor adequação em casos como esse.

Os resultados da estimação pelo método POLS demonstraram que há significância estatística para a maioria dos indicadores, dentre eles: fluxo de caixa livre/preço (FCF/P), liquidez corrente (LIQ), endividamento (END), margem bruta (MB), lucro/preço (L/P), dividend yield (DY) e vendas/preço (V/P). Porém não foi encontrada significância estatística para os indicadores margem bruta (MB) e dividend yield (DY), em desacordo com a teoria.

Ademais, foi realizado a estimação do modelo por um painel dinâmico, o qual demonstrou que o fluxo de caixa livre/preço (FCF/P) de um trimestre possui relação com o retorno acionário (RET) do próximo trimestre e para dois trimestres seguintes. Essa relação fornece evidências empíricas quanto as anomalias de mercado estudadas por Famá, Oda e Yoshinaga (2003) e Famá, Cioffi e Coelho (2008), as quais dizem que nem toda informação disponível no período são incorporadas como retorno acionário das companhias.

O presente trabalho avança em relação à literatura empírica da contabilidade no mercado de capitais ao revelar que o índice de mercado fluxo de caixa livre/preço (FCF/P) é capaz de prever o retorno acionário (RET), principalmente com um e três trimestres de defasagem, de modo que os investidores do mercado de capitais podem direcionar mais a sua atenção para o fluxo de caixa livre (FCF) ao fazer projeções futuras para o valor das companhias e também para montagem de carteiras.

Como sugestão de pesquisa futura, pode-se utilizar o indicador fluxo de caixa/preço (FCF/P) para estratégias de investimento e verificar se, assim, é possível obter retornos anormais para os investidores. As principais limitações da pesquisa foram a pequena quantidade de amostra, já que há poucas companhias de capital aberto no Brasil quando se compara a outros mercados, e as mudanças e adequação das políticas contábeis no período analisado.

\section{REFERENNCIAS}

ABRABANELL, J. S.; BUSHEE, B. J. Abnormal Returns to a Fundamental Analysis Strategy. The Accounting Review, v. 73, n. 2, p. 19-45, 1998.

. Fundamental analysis, future earnings, and stock prices, Journal of Accounting Research, v. 35, n. 1, p. 1-24, 1997.

ARELLANO, M.; BOND, S. Some tests of specification for panel data: Monte Carlo evidence and an application to employment equations, Review of Economics Studies, v. 58, n.1, p. 277-297, 1991.

ASSAF NETO, A. Estrutura e Análise de Balanços: Um Enfoque Econômico-Financeiro. 9a ed. São Paulo: Atlas, 2010.

Finanças Corporativas e Valor. $6^{a}$ ed. São Paulo: Atlas, 2012.

Mercado Financeiro. 12 a ed. São Paulo: Atlas, 2014.

BASTOS, D. D.; NAKAMURA, W. T.; DAVID, M.; ROTTA, U. A. S. A relação entre o retorno das ações e as métricas de desempenho: evidências empíricas para as companhias abertas no Brasil. Revista de Gestão, v. 16, n. 3, art. 5, p. 65-79, 2009.

BARBEE JR., W. C.; MUKHERJI, S.; RAINES, G. A. Do sales-price and debt-equity explain stock returns better than book-market and firm size? Financial Analysts Journal, v. 52, n. 2, p. 56-60, 1996.

BLACK, Fischer. Capital market equilibrium with restricted borrowing. The Journal of Business, v. 45, n. 3, p. 444-455, 1972.

COMITÊ DE PRONUNCIAMENTOS CONTÁBEIS (CPC). CPC 00, Estrutura Conceitual para a Elaboração e Divulgação de Relatório Contábil-Financeiro. Disponível em < http://static.cpc.mediagroup.com.br/Documentos/147_CPC00_R1.pdf> Acesso em 11 de junho de 2017.

COPELAND, T.; KOLLER, T.; MURRIN, J. Avaliação de Empresas: Valuation. $3^{\text {a }}$ ed. São Paulo: Makron, 2002.

COSTA JR., N. C. A.; NEVES, M. B. E. das. Variáveis Fundamentalistas e Retornos das Ações. In: Mercado de Capitais: Análise Empírica no Brasil. São Paulo: Atlas, 2000.

DAMODARAN, A. Avaliação de Investimentos: Ferramentas e Técnicas para a Determinação do Valor de Qualquer Ativo. Qualitymark: Rio de Janeiro, 1997. 
EVRARD, H. S.; CRUZ, J. A. W.; Indicadores financeiros e de mercado para previsão do retorno de ações do Ibovespa entre os anos de 2003 e 2013. Sociedade, Contabilidade e Gestão, v. 11, n. 1, Rio de Janeiro, 2016.

FAMA, Eugene F. Efficient capital markets: II. The journal of finance, v. 46, n. 5, p. 1575-1617, 1991.

FAMA, Eugene F.; FRENCH, Kenneth R. Common risk factors in the returns on stocks e bonds. Journal of Financial Economics, v. 33, n. 1, p. 3-56. 1993.

FAMA, Eugene F; FRENCH, Kenneth R. Multifactor explanations of asset pricing anomalies. The journal of finance, v. $51, n$. 1, p. 55-84, 1996.

FAMÁ, R.; ODA, A. L.; YOSHINAGA, C. E. Análise da Sobre-reação de Preços no Mercado Brasileiro de 1995 a 2003. Caderno de Pesquisas em Administração, São Paulo, v. 3, n. 2, 2003.

FAMÁ, Rubens; DE MORAES CIOFFI, Patrícia Leite; COELHO, Paula Augusta Rodrigues. Contexto das finanças comportamentais: anomalias e eficiência do mercado de capitais brasileiro. REGE Revista de Gestão, v. 15, n. 2, p. 65-78, 2008.

FÁVERO, L. P. Análise de Dados: Modelos de Regressão com Excel®, Stata® e SPSS®. Rio de Janeiro: Campus, 2013.

FELLET, Bianca Gabriel. Avaliação de Modelos de Precificação de Ativos no Mercado Acionário Brasileiro. Brasília, 2016. Dissertação (Mestrado em Ciências Contábeis). Programa Multiinstitucional e Inter-Regional de Pós-Graduação em Ciências Contábeis (UnB/ UFPB/UFRN). Universidade de Brasília. Faculdade de Economia, Administração e Ciências Contábeis e Atuariais.

FERREIRA, J. K. F. S. A Significância dos Indicadores Fundamentalistas na Explicação do Retorno das Ações: Uma Análise no Setor de Siderurgia e Metalurgia Brasileiro. Dissertação de Mestrado. Universidade Federal de Pernambuco. Pernambuco, 2010.

GALDI, F. C.; LOPES, R. F. Avaliação de ações e números contábeis: aplicação dos modelos de Zhang (2000) e Zhang e Chen (2007) no mercado brasileiro. Revista Brasileira de Finanças, v. 9, n. 1, p. 131-157, Rio de Janeiro, 2011.

GREIG, A. C. Fundamental analysis ans subsequente stock returns. Journal of Accounting and Economics, v. 15, p. 423-442, 1992.

GUJARATI, D. N. Basic Econometrics. 4a ed. McGraw Hill, 2003.

HOLTHAUSEN, R. W.; LARCKER, D. F. The Prediction of Stock Returns Using Financial Statement Information. Journal of Accounting and Economics, v.15, n. 2-3, p. 373-411, 1992.

IUDÍCIBUS, S. Análise de Balanços. $7^{\text {a }}$ ed. São Paulo: Atlas, 1998.

JEGADEESH, Narasimhan; TITMAN, Sheridan. Returns to buying winners and selling losers: Implications for stock market efficiency. The Journal of finance, v. 48, n. 1, p. 65-91, 1993.

KOTHARI, S. P. Capital Markets Research in Accounting. Journal of Accounting and Economics, v. 31, p. 105-231, 2001.

LEV, B.; THIAGARAJAN, R. Fundamental Information Analysis. Journal of Accounting Research, v. 31, p. 190-215, 1993.

LEWELLEN, J. Predicting Returns With Financial Ratios. Journal of Financial Economics, v. 74, p. 209-235, 2002.

LINTNER, John. The Valuation of Risk Assets and the Selection of Risky Investments in Stock Portfolios and Capital Budgets. Review of Economics and Statistics, v. 47, n. 1, p. 13-37, 1965.

MALKIEL, Burton G.; FAMA, Eugene F. Efficient capital markets: A review of theory and empirical work. The journal of Finance, v. 25 , n. 2 , p. $383-417,1970$.

MALTA, T. L.; CAMARGOS, M. A. Variáveis da Análise Fundamentalista e Dinâmica e o Retorno Acionário de Empresas Brasileiras Entre 2007 e 2014. REGE - Revista de Gestão v. 23, n. 1, p. 52-62, 2016.

MARKOWITZ, Harry. Portfolio Selection. The Journal of Finance, v. 7, n. 1, p. 77-91, 1952.

MARTINS, E. et al. Avaliação de Empresas: Da Mensuração Contábil à Econômica. São Paulo: Atlas, 2001.

MOHANRAM, P. S. Separating winners from losers among low book-to-market stocks using $\square$ nancial statement analysis. Review of Accounting Studies, v. 10, p. 133-170, 2005.

MOSSIN, Jan. Equilibrium in a Capital Asset Market. Econometrica, v. 34, n. 4, p. 768-783, 1966.

NAGANO, M. S.; MERLO, E. M.; SILVA, M. C. As variáveis fundamentalistas e seus impactos na taxa de retorno das ações no Brasil. Revista FAE, Curitiba, v. 6, n. 2, p. 13-28, 2003.

OU, J.; PENMAN, S. H. Accounting measurement, price-earnings ratios, and the information content of security prices, Journal of Accounting Research, v. 27, n. 2, p. 111-152, 1989a. $295-3 \overline{29,1989 b}$

Financial statement analysis and the prediction of stock returns, Journal of Accounting \& Economics, v. 11, n. 3, p.

O'BRIEN, Thomas J. The global CAPM and a firm's cost of capital in different currencies. Journal of Applied Corporate Finance, v. 12, n. 3, p. 73-79, 1999.

PENMAN, S. H. Return to fundamentals. Journal of Accounting, Auditing and Finance, v. 7, n. 4, p. 465-482, 1992.

PEREIRO, Luis E. The valuation of closely-held companies in Latin America. Emerging Markets Review, v. 2, n. 4, p. 330-370, 2001.

PIOTROSKI, J. D. Value Investing: The Use of Historical Financial Statement Information to Separate Winners from Losers. Journal of Accounting Research, v. 38, p. 1-41, 2000.

PÓVOA, A. Valuation: Como Precificar Ações. Campus: Rio de Janeiro, 2012. 
RANGEL, L. L. A Relevância dos Indicadores Contábeis para Estimativa de Retorno das Ações Negociadas na Bovespa: Um Estudo Empírico no Setor de Metalurgia e Siderurgia. Dissertação de Mestrado. Fundação Instituto Capixaba de Pesquisas em Contabilidade, Economia e Finanças - FUCAPE. Vitória, 2004.

ROSS, Stephen A. The arbitrage theory of capital asset pricing. Journal of Economic Theory, v. 13, n. 3, p. 341-360, 1976.

SHARPE, William F. Capital Asset Prices: A Theory of Market Equilibrium Under Conditions of Risk. Journal of Finance, v. 19, n. 3, p. 425-442, 1964

STOBER, T. L. Summary financial statement measures and financial analysts' forecasts of earnings. Journal of Accounting and Economics, v. 15, p. 347-372, 1992

TAVARES, A. L.; SILVA, C. A. T. A Análise Financeira Fundamentalista na Previsão de Melhores e Piores Alternativas de Investimento. Revista Universo Contábil, v. 8, p. 37-52. Blumenau, 2012.

TOBIN, James. Liquidity preference as behavior towards risk. The review of economic studies, v. 25, n. 2, p. 65-86, 1958

TREYNOR, Jack L. Toward a theory of market value of risky assets. Unpublished manuscript, v. 6, p. 831-868, 1961.

YAN, X.; ZHENG, L. Fundamental analysis and the cross-section of stock returns: a data mining approach. The Review of Financial Studies, v. 30, n. 4, p. 1382-1423, 2017. 